\title{
Literature and patent analysis of the cloning and identification of human functional genes in China
}

\author{
XIA Yan ${ }^{1}$, TANG LiSha ${ }^{1}$, YAO Lei ${ }^{1}$, WAN Bo ${ }^{1}$, YANG XianMei $^{1} \&$ YU Long ${ }^{1,2 *}$ \\ ${ }^{1}$ State Key Laboratory of Genetic Engineering, School of Life Sciences, Fudan University, Shanghai 200433, China; \\ ${ }^{2}$ Institutes of Biomedical Sciences, Fudan University, Shanghai 200032, China
}

Received August 27, 2011; accepted October 13, 2011

\begin{abstract}
The Human Genome Project was launched at the end of the 1980s. Since then, the cloning and identification of functional genes has been a major focus of research across the world. In China too, the potentially profound impact of such studies on the life sciences and on human health was realized, and relevant studies were initiated in the 1990s. To advance China's involvement in the Human Genome Project, in the mid-1990s, Committee of Experts in Biology from National High Technology Research and Development Program of China (863 Program) proposed the "two 1\%" goal. This goal envisaged China contributing $1 \%$ of the total sequencing work, and cloning and identifying $1 \%$ of the total human functional genes. Over the past 20 years, tremendous achievement has been accomplished by Chinese scientists. It is well known that scientists in China finished the $1 \%$ of sequencing work of the Human Genome Project, whereas, there is no comprehensive report about "whether China had finished cloning and identifying $1 \%$ of human functional genes". In the present study, the GenBank database at the National Center of Biotechnology Information, the PubMed search tool, and the patent database of the State Intellectual Property Office, China, were used to retrieve entries based on two screening standards: (i) Were the newly cloned and identified genes first reported by Chinese scientists? (ii) Were the Chinese scientists awarded the gene sequence patent? Entries were retrieved from the databases up to the cut-off date of 30 June 2011 and the obtained data were analyzed further. The results showed that 589 new human functional genes were first reported by Chinese scientists and 159 gene sequences were patented (http://gene.fudan.sh.cn/ introduction/database/chinagene/chinagene.html). This study systematically summarizes China's contributions to human functional genomics research and answers the question "has China finished cloning and identifying $1 \%$ of human functional genes?" in the affirmative.
\end{abstract}

gene cloning, gene identification, human functional gene

Citation: Xia Y, Tang L S, Yao L, et al. Literature and patent analysis of the cloning and identification of human functional genes in China. Sci China Life Sci, 2012, 55: 268-282, doi: 10.1007/s11427-012-4299-6

DNA sequencing began in the early 1970s $[1,2]$. However, it was only after Sanger et al. [3] introduced the dideoxy-mediated chain-termination method that the efficiency and accuracy of DNA sequencing increased dramatically. Subsequent breakthroughs in sequencing technologies led in 1985 to some US scientists suggesting that the sequencing of the human genome would now be possible. And so it was, in 1990 , that scientists from different countries officially

*Corresponding author (email: longyu @ fudan.edu.cn) launched the Human Genome Project (HGP). On 26 June 2000, China, the United States, Britain, Japan, Germany and France declared the publication of a working draft of the human genome. In April 2003, a fine-scale genetic map of the human genome was published [4]. These achievements are of historic significance to the development of the life sciences and health care. China joined the HGP in September 1999 and accepted the job of sequencing approximately $30 \mathrm{Mb}$ on the short arm of chromosome 3 (human); this accounted for $1 \%$ of the human genome. Although the hu- 
man genome sequence is now almost complete, it does not mean that the functions of the genes have been fully understood. The predicted number of human functional genes has dropped from 100000 to 30000; however, studies on gene functions lag far behind the sequencing work of the genome. Clearly, the study of gene functions will be at the core of the life science for a very long time to come.

Gene cloning and identification are essential steps in the study of gene function. Long before the initiation of HGP, scientists had begun to clone and identify human functional genes. The human growth hormone [5] and human fetal gamma globulin [6] were among some of the first genes to be cloned and identified. Later, advances in sequencing techniques and computer sciences helped accelerate the cloning and identification of genes. The advent of in silico cloning also greatly expedited human genomics research. Recently, the emergence of large-scale, high throughput genomic sequencing techniques have meant that more complete genomic sequences are being determined and this information has significantly contributed to the cloning and identification of human functional genes.

Chinese scientists began to clone and identify human functional genes in the early 1990s [7,8], but progress was slow. In the mid-1990s, a Committee of Experts in Biology from the National High Technology Research and Development Program (863 Program) proposed the "two 1\%" goal which involved the inclusion of China in the HGP by contributing $1 \%$ of the total sequencing work, and by cloning and identifying $1 \%$ of the total human functional genes. With the support of the Ministry of Science and Technology of China and the National Natural Science Foundation of China, equipment and scientific research personnel for human gene cloning and identification increased substantially. As a result of this support, developments in gene cloning and identification started to accelerate in China and China's work in functional genomics caught up with the rest of the world.

Because of its profound scientific research value and economic interests, governments and multinational enterprises have invested large amounts of manpower and money into human functional genomics research. The Chinese government and related research institutes have also paid much attention to the study of human functional genomics. However, no comprehensive report concerning the current status of human functional genomics research in China is currently available. To elucidate China's progress in human genomics eleven years after the completion of the first working draft of the human genome sequence, the present study aimed to ascertain which of the human functional genes were first cloned and identified by Chinese researchers. Databases were searched using two screening standards: (i) Were the new genes that were published in international journals, first cloned and identified by Chinese scientists? (ii) Were the genes patented? A summary of China's accomplishment in cloning and identifying human functional genes is presented here.

\section{Materials and methods}

Human genome data were downloaded from the National Center of Biotechnology Information (NCBI) server (ftp://ftp.ncbi.nih.gov/genomes/H_sapiens/). The human genome data was analyzed and protein coding sequences and their Accession Numbers were obtained. The Accession Numbers were searched against the GenBank database and the retrieved entries were checked to find whether or not they were annotated with literature references; entries with no literature references were excluded from the analysis. Other literature references that were excluded reported only large-scale sequencing, databases, network regulation and control, gene mutations or mononucleotide polymorphisms, cloning of gene promoters, pseudogenes, spliced variants of the same gene, isomers and/or non-human genes. From the list of screened literature, the first paper on a particular gene that was published after 1985 was assumed to be the first report of that gene's cloning and identification. The first named institution, the authors' country and other information were retrieved from PubMed using the search system. The genes that were first reported by Chinese scientists were listed, and each one was manually checked. The collected data was then used to identify research groups that had multiple publications. Next, we used the corresponding authors' name and affiliation as keywords in the PubMed search system to retrieve additional papers that reported the first time cloning and/or identification of a human gene by Chinese researchers. We used the keywords polynucleotide, polypeptide, and sequence in an advanced search of the abstract to retrieve records from the patent database of the State Intellectual Property Office of China (http://www. sipo.gov.cn/) about patents that were issued for human functional gene sequences. Unauthorized patents and patent applications not made by China agencies were excluded. Inventors with multiple patents were listed and their names were used as keywords to search the patent database once again. All the retrieved data were combined to obtain a data set that contained human functional genes that had been cloned and identified by Chinese scientists working in China. Then all the results in the final data set were manually checked before being analyzed.

\section{Results}

\subsection{Reported genes}

The human genome data that was downloaded from the NCBI server contained 43159 genes with sequences that were clearly annotated as protein-coding, RNA gene or pseudogene, and others. There were 34511 protein-coding genes in the data set. To understand the work of each coun- 
try in cloning and identifying human functional genes, the 17428 protein-coding genes that had literature annotations were manually screened and, after screening with the previous standards, 14944 human protein-coding genes were obtained. By identifying the country of the first named institution that first reported a particular gene, we obtained a rough estimate of the contribution of each country to cloning and identifying human functional genes (Figure 1B).

The six countries that participated in the HGP (United States, Japan, Germany, Britain, France and China) cloned and identified $76.01 \%$ of the estimated number of human functional genes. By taking part in the HGP, these countries developed and demonstrated their advantage in cloning and identifying human functional genes.

The literature annotation obtained using the NCBI human genomic Accession Numbers is incomplete because of the complexity and lag time of the literature annotations being entered into the database. As a result, many genes are either not annotated or only partially annotated. To find more information on the Chinese contribution to functional gene cloning, a list of corresponding authors with many published papers and their affiliations were extracted from the existing literature annotations. The names and affiliations were used as keywords in the PubMed search system to retrieve additional relevant papers and human functional genes that were first reported by Chinese scientists. The results of this search complemented the result first obtained by searching GenBank.

Until 30 June 2011, 544 papers by Chinese scientists reported, for the first time, the cloning and identification of 589 new human functional genes (http://gene.fudan.sh. $\mathrm{cn} /$ introduction/database/chinagene/chinagene.html). Of the 589 genes, 523 were cloned in mainland China, 25 in Hong Kong and 41 in Taiwan (Figure 2A). The 544 papers were analyzed in terms of impact factor (IF), number of times cited, year of publication, first named institution in the publication, and gene function (based on the Gene Ontology). The number of times the paper was cited was obtained from the Web of Knowledge (http://apps.webofknowledge.com/); the data are collected up to 30 June 2011. The IF was obtained from the Web of Knowledge, Journal Citation Reports, Science; the IF for 2010 was used in this study.

A study on the gene NYD-SP27 [10] conducted by scientists at the Chinese University of Hong Kong in 2003 was published in Lancet (IF=33.633). This journal has the highest IF of all the journals in which Chinese scientists have reported (for the first time) the cloning and identification of a new gene. In general, more than half (342/544) these reports were published in low-IF journals $(\mathrm{IF}=1-5)$. Only 14 papers $(2.57 \%)$ were published in journals with an IF higher than 10; they included 11 papers published by researchers in mainland China. These 11 papers reported the genes Apak [11], OLC1 [12], LPTS [13], LZP [14], ALC1 [15], Hsp70L1 [16], KLRL1 [17], HAPO [18], ZBTB16 [19], SIKE1 [20] and SIP [21]; of these, the Apak [11] study was published in the journal with the highest IF (Nature Cell Biology, IF=19.407). Up until 30 June 2011, together these papers had been cited 5909, an average of 10.9 times per paper (Figure 2C). In 1993, a research group led by Chen Zhu from the Ruijin Hospital, Shanghai Jiao Tong University reported the cloning and identification of the gene ZBTB16 and its role in acute promyelocytic leukemia in $E M B O$ Journal [19]; of all the 544 first report papers, this one has been cited the most number of times (447 times). However, $72.06 \%(392 / 544)$ of the papers have been cited less than 10 times and 91 papers have never been cited; this observation reflects a lack of influence of the results of these reports.

Of the 43 papers that have been cited more than 30 times, 32 were published from mainland China $(74.4 \%)$. The reported genes include ZBTB16 [19], NDRG2 [22], and TRAF19 [23], among others. Chinese scientists started to report the cloning and identification of human functional genes in the 1990s (Figure 2D). In 1990, a group led by Zhong BangZhu from the Institute of Biochemistry and Cell Biology, Academia Sinica, Taiwan, studied the structure, sequencing, chromosome localization and evolution of the FDX1 gene from the human ferredoxin gene family [7]. Their work was the first Chinese study to be recorded in the
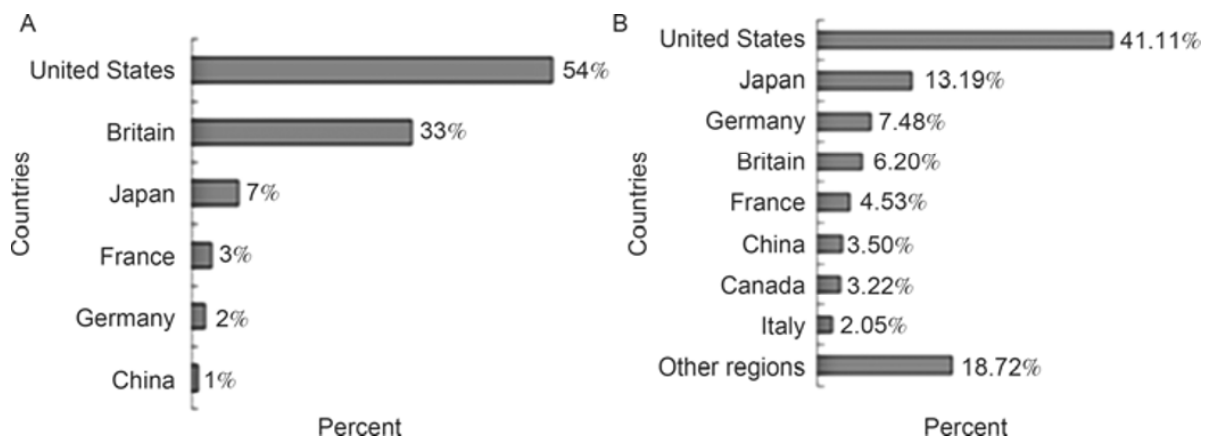

Figure 1 Comparison of the work of different countries in sequencing, cloning and identification of human functional genes (till 30 June 2011). A, Sequencing finished by the different countries in the HGP [9]. China undertook the sequencing of 30 Mb of the DNA on the short arm of chromosome 3; approximately $1 \%$ of the total human genome sequence. B, Number of genes cloned and identified by the different countries: US 6143, Japan 1971, Germany 1118, Britain 927, France 677, Mainland China about 523, Canada about 481, Italy about 307, and other countries and regions 2797. Mainland China is ranked number 6 in the list of countries involved in the HGP. 

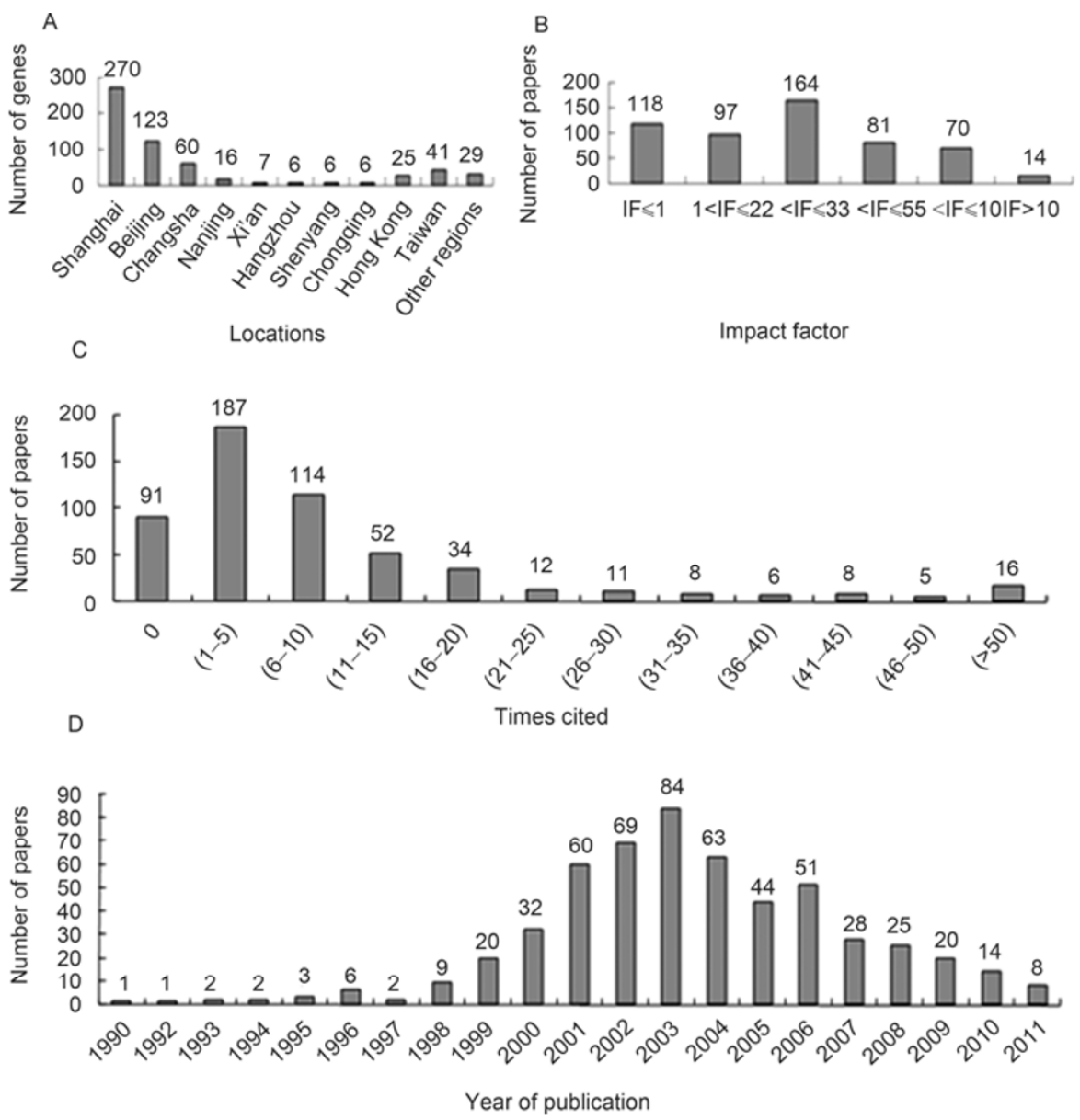

Figure 2 Analysis of the literature in which human functional genes first cloned and identified by Chinese scientists were reported (till 30 June 2011 ). A, Number of genes that were reported from the different locations. Shanghai accounts for $45.84 \%$ and is followed by Beijing and Changsha. B, The impact factor (IF) of the journals in which the reports were first published. Most of the papers $(84.56 \%$ ) were published in journals with a low IF (IF $\leqslant 5$ ). C, The number of times a paper has been cited. 66 papers have been cited more than 20 times; however, most $(72.06 \%)$ have been cited less than 10 times. D, Number of papers published by year of publication. The largest number of publications appeared in 2003.

NCBI database. The first study from mainland China was conducted by a group led by Wang LinFang from the Chinese Academy of Medical Sciences. They successfully cloned an infertility associated gene HSD-3.8 encoding a testis-specific protein [8]. The work of cloning and identifying human functional genes that has been carried out in China could be divided into three stages: (i) Before 1999, only a few papers were published and most research groups were still learning; (ii) from 2000 to 2003 , as technology platforms in the various laboratories improved, more genes were being reported first by Chinese researchers; and (iii) after 2004, as the cloning and identification of human functional genes ceased to be the focus of scientific research, the number of papers in the field declined. The focus has now transferred to the study of the biological function of these genes. Quite early on, researchers at Fudan University in Shanghai established various human cDNA libraries and implemented large-scale sequencing analyses; as a result, 175 articles reporting gene cloning and identification have been published. A total of 192 human functional genes have been reported; most of them were studied at the State Key Laboratory of Genetic Engineering, Fudan University (Table 1). In

Table 1 Number of papers and genes published by Chinese scientists on the cloning and identification of human functional genes (till 30 June 2011)

\begin{tabular}{ccc}
\hline First named institution & $\begin{array}{c}\text { Number } \\
\text { of papers }\end{array}$ & $\begin{array}{c}\text { Number } \\
\text { of genes }\end{array}$ \\
\hline Fudan University & 175 & 192 \\
Peking University & 39 & 54 \\
Chinese Academy of Medical Sciences & 39 & 39 \\
Hunan Normal University & 33 & 34 \\
Second Military Medical University of PLA & 32 & 32 \\
Central South University & 23 & 23 \\
Shanghai Institutes for Biological Sciences, & 18 & 18 \\
Chinese Academy of Sciences & 15 & 15 \\
Shanghai Jiao Tong University & 14 & 14 \\
Nanjing Medical University & 12 & 14 \\
Beijing Institute of Radiation Medicine & 63 & 66 \\
Hong Kong and Taiwan & 81 & 88 \\
Others & 544 & 589 \\
Total &
\end{tabular}


the present study, we performed a Gene Ontology [24] analysis on the human functional genes first cloned and identified by Chinese researchers. We also conducted a statistical analysis of these genes and analyzed their function at the molecular level (Figure 3A), their biological function at the cellular level (Figure 3B), and/or their possible macroscopic biological functions by referring to relevant literature (Figure 3C).

\subsection{Human functional genes reported in authorized patents}

Many foreign corporations and enterprises have registered a succession of human functional gene for patents. Because of the importance of filing patent applications for human functional genes with potentially valuable applications, scientific research institutions and companies in China also began to apply for gene patents. A search of the patent database of the State Intellectual Property Office of China (http://gene.fudan.sh.cn/introduction/database/chinagene/chi nagene.html) up until 30 June 2011, found 159 human gene sequences that had been patented by Chinese scientists. Most of the agencies and companies that had applied for patents had substantial scientific research resources and were located in Shanghai or Beijing (Figure 4A). Applications for tumor-associated genes were the highest; these were followed by immunity-associated genes (Figure 4B). In addition, most of the patent applications came from sci-
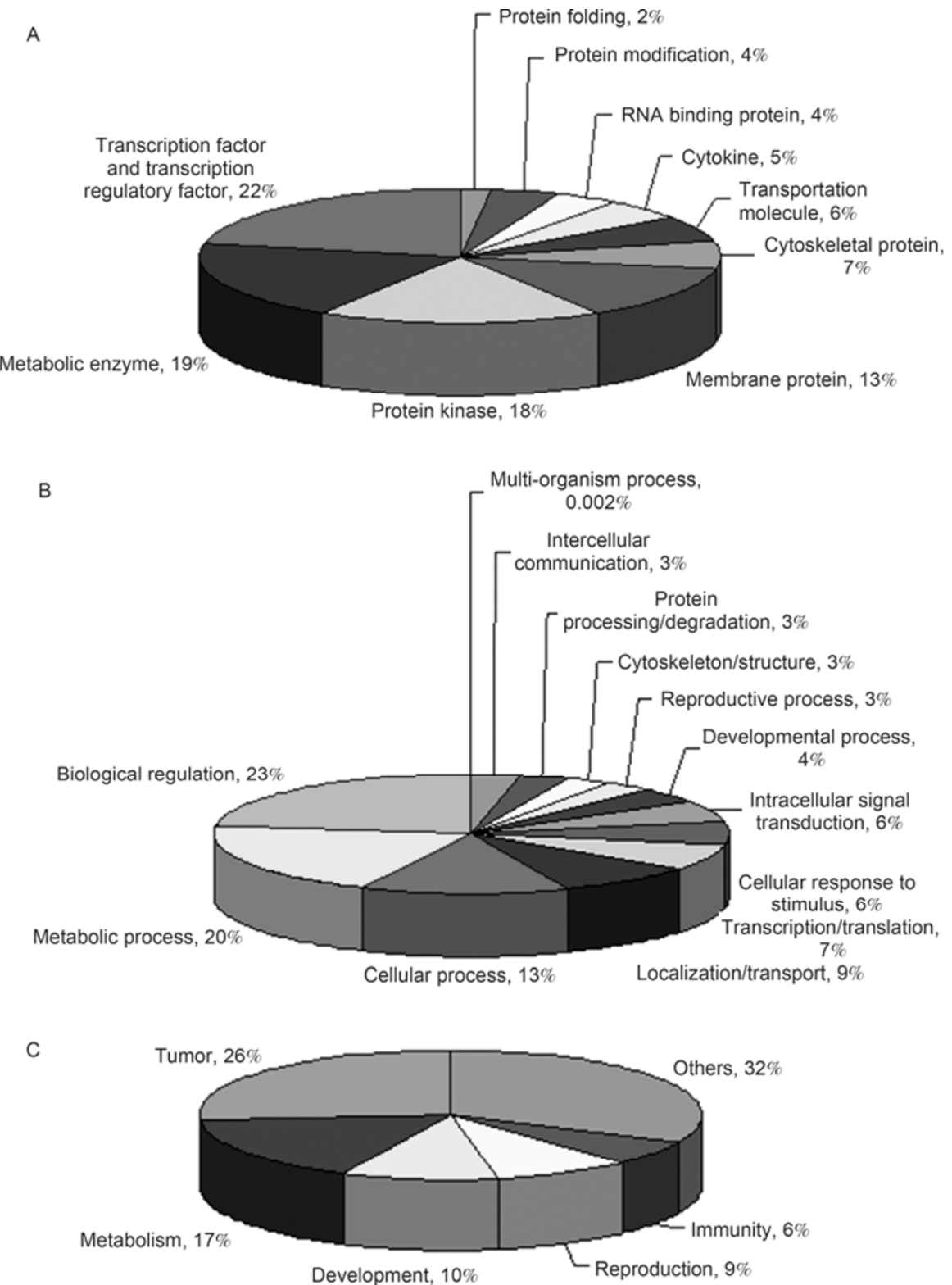

Figure 3 Classification of human functional genes cloned and identified by Chinese scientists at the molecular, cellular and macroscopic function levels. A, Gene ontology classification of the functions of the genes at the molecular level. B, Gene ontology classification of the functions of the genes at the cellular level. C, Classification of the possible macroscopic biological functions of the genes from information in the published literature. 
entific research institutions rather than from enterprises (Figure 4C). A group led by Gu Jianren (major inventor) has been awarded 50 patents for gene sequences (Table 2) most of which were liver cancer-associated markers or cancer suppressor genes. Of the 159 patented gene sequences, 25 received patents from United States [25-49], three received patents from European Union [50-52] and two from Canada [53,54].

\section{Discussion}

In this study, the Chinese contribution to human functional gene cloning and identification in the past 20 years has been reviewed. By collecting and analyzing articles (first published by Chinese scientists) and issued patents, we discovered that Chinese scientists have achieved a lot in the fields of tumor, reproduction, immunity and development. Some representative achievements are described in this section.

Some of the 192 new human functional genes first reported by researchers at the State Key Laboratory of Genetic Engineering, Fudan University are described here. TRPT1 [55] encodes tRNA 2'-phosphotransferase which participates in the splicing and maturity of pre-tRNA's and complements the tpt 1 mutation in Saccharomyces cerevisiae; ITPA, [56] cloned from a human fetal brain cDNA library,
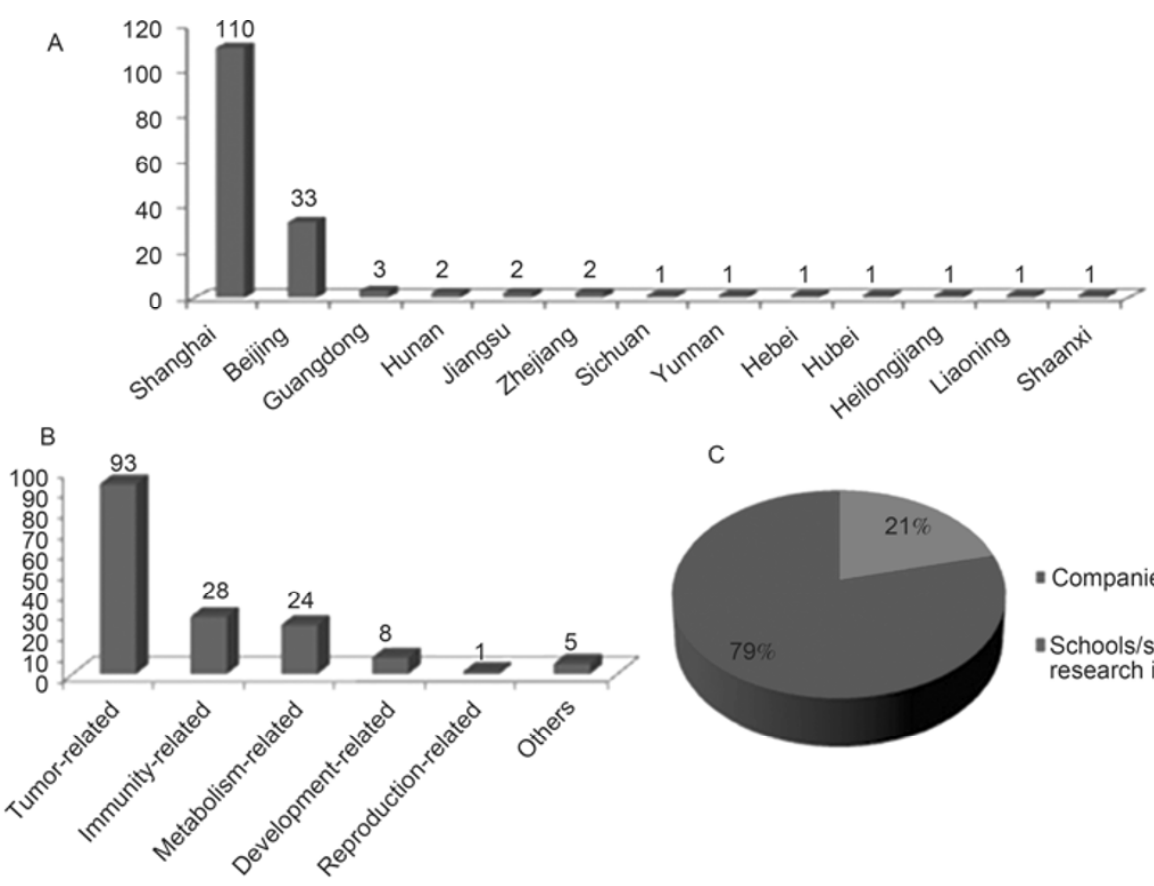

C

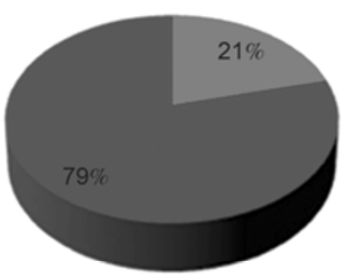

Companies

- Schools/scientific

research institutions

Figure 4 Patents for human functional genes issued to Chinese scientists. A, Regions in China from which patent applications for human functional genes were filed. B, Patents classified according to the functions of the patented genes. C, Patents classified according to the source of the application.

Table 2 Number of patent applications and issued patents for gene sequences from the Chinese and international patent databases

\begin{tabular}{|c|c|c|c|c|c|c|c|}
\hline \multirow{2}{*}{ Major inventor } & \multirow{2}{*}{$\begin{array}{l}\text { Issued patents } \\
\text { from China }\end{array}$} & \multirow{2}{*}{$\begin{array}{l}\text { Issued gene sequence } \\
\text { patents from China }\end{array}$} & \multicolumn{2}{|c|}{ Applicants (patent holder) } & \multicolumn{3}{|c|}{$\begin{array}{l}\text { Issued gene sequence patent } \\
\text { from foreign countries }\end{array}$} \\
\hline & & & $\begin{array}{l}\text { School/scientific } \\
\text { research institution }\end{array}$ & Enterprise & US & EU & Canada \\
\hline Gu JianRen & 57 & 50 & 30 & 20 & 2 & 0 & 0 \\
\hline Yu Long & 39 & 14 & 11 & 3 & 7 & 3 & 2 \\
\hline Cao XueTao & 19 & 14 & 14 & 0 & 0 & 0 & 0 \\
\hline Ma DaLong & 20 & 6 & 5 & 1 & 2 & 0 & 0 \\
\hline Chang ZhiJie & 20 & 5 & 5 & 0 & 1 & 0 & 0 \\
\hline Zhao MuJun & 7 & 4 & 4 & 0 & 1 & 0 & 0 \\
\hline Wang HongYang & 4 & 3 & 3 & 0 & 0 & 0 & 0 \\
\hline Wu XiuShan & 2 & 2 & 2 & 0 & 0 & 0 & 0 \\
\hline He Lin & 15 & 2 & 2 & 0 & 0 & 0 & 0 \\
\hline He FuChu & 6 & 1 & 1 & 0 & 0 & 0 & 0 \\
\hline Mao YuMing & 10 & 0 & 0 & 0 & 12 & 0 & 0 \\
\hline Others & & 58 & 48 & 10 & - & - & - \\
\hline Total & & 159 & 125 & 34 & 25 & 3 & 2 \\
\hline
\end{tabular}


encodes inosine triphosphate pyrophosphatase which can eliminate minor potentially mutagenic or clastogenic purine nucleoside triphosphates from the cell; $P K I B$ and $P K I G$ [57] encode genes that belong to the human cAMP-dependent protein kinase inhibitor (PKI) family and regulate the activity of cAMP-dependent protein kinase; ATP5E [58] encodes the epsilon subunit of human ATP synthase; and CRYLI [59] displays a much lower expression level in liver cancer tissue than in normal liver tissue. CRYL1 was found to be down-regulated in $58 \%$ of 60 Chinese human hepatocellular carcinoma (HCC) tissue samples, suggesting that it might be a candidate cancer suppressor gene. In addition, nine small GTPases [60] were cloned and identified, and they were shown to participate in vesicle transportation which is responsible for the maintenance of normal liver function. The GTPases were also found to exhibit changes in expression in multiple liver cancer samples; in addition, the expression level of PPAPDC1B was found to be much lower in metastatic tumor tissues than in primary HCC tissues. Both in vitro and in vivo assays suggested that $P P A P D C 1 B$ could suppress the invasion and metastasis of HCC and it was proposed that PPAPDC1B could be a novel metastatic suppressor gene for HCC [61]. The proteins encoded by $M A P 1 L C 3 A, M A P 1 L C 3 B$ and MAPILC3C participate in cellular autophagy and a new post-translational modification mechanism of the MAP1LC3B protein was discovered [62]. Using a human fetal brain cDNA library, a number of brain development associated genes were identified; they include BTBD8 [63], C14orf5 [64], C4orf13 [65], and SEC14L3 [66]. Moreover, HN1 and HN1L were proposed to be involved in embryo development [67]. A number of reproduction-associated genes were cloned; for example, PPP3RL [68] was found to play an important role in the testicular maturation and spermatogenesis, and the NDRG3 [69] mRNA was localized to the outer layers of seminiferous epithelium. Therefore, it is supposed that NDRG3 is related to spermatogenesis. Moreover, one of the groups led by $\mathrm{Yu}$ Long was awarded 14 patents for new human genes that include LYC1 [70], LYC2 [71], and LYC3 [72] which belong to the lysosome gene family and human UMP-CMP kinase [73].

At the Institute of Hematology, Ruijin Hospital, Shanghai Jiao Tong University, researchers studied leukemia and elucidated the important role of ZBTB16 in the onset of acute promyelocytic leukemia (APL) [19]. This discovery was a major breakthrough in the study of APL. In addition, the IFIT3 [74], and LY6E [75] genes that were found to facilitate differentiation during the induction treatment of APL using all-trans retinoic acid (ATRA) were cloned and identified. This was a significant contribution to the understanding of the cellular and molecular mechanism of APL which helped modify the treatment strategy. Researchers at the Shanghai Cancer Institute performed large-scale sequencing of the genomic DNA on the short arm of chromosome 17 . As a result of this work, many genes related to the genesis of liver cancer, including RNMTL1 [76], GLOD4 [77], and HCCS1 [78], have been identified and a large number of patents associated with the diagnosis and treatment of liver cancer have been issued. For example, MAGEDI [79] and TSP1 [80] are novel markers for liver cancer that can be used in its diagnosis, and BNIPL that can suppress the growth of HCC cells and promote its apoptosis [81]. LZP [14] was cloned at the Chinese National Human Genome Center, Shanghai, and the data suggest that $L Z P$ encodes a liver-specific protein that may be involved in hepatocellular function and development; it was proposed that the $L Z P$ protein could be a potential negative biomarker for HCC pathologic diagnosis. In addition, six zinc finger protein genes that participate in the regulation of transcription were cloned from a hematopoietic cell line [82].

Researchers at the Institute of Biochemistry and Cell Biology, Shanghai Institute of Biological Sciences, Chinese Academy of Sciences identified BTBD7 as a new gene related to the tumorigenesis of HCC. Relevant studies showed that it could stimulate NIH3T3 cell proliferation and tumor formation in nude mice [83]. By representational difference analysis (RDA), a novel human gene $S V H$ that was up-regulated in a clinical HCC sample was identified. $S V H$ has four splicing variants, $S V H-A, S V H-B, S V H-C$ and $S V H-D$; however, experimental results showed that only $S V H-B$ seemed to play an important role in hepatocarcinogenesis [84]. Two genes located in the region of the short arm of chromosome 8 have also been cloned, and in human hepatocellular carcinoma, this region was found to show a rapid loss of heterozygosity. Experimental evidence that LPTS [13] and VPS37A [85] encode growth inhibitory proteins for human liver cancer cells and that VPS37A is associated with the decreasing of the invasion of HCC cells was also reported. In addition, it was found that $D E F B 118$ is specifically expressed in the epididymis where it can promote fertility by protecting sperm against attack by bacteria or viruses in the male and female reproductive tracts [86]. Human Pifl encodes a helicase that reduces telomerase processivity and unwinds the DNA/RNA duplex in vitro, and it was proposed that the mechanism by which human Pifl inhibits telomerase probably involves unwinding of the DNA/RNA duplex [87]. CIDE-3 encodes a novel family member of cell-death-inducing DFF45-like effectors (CIDEs), induces cellular apoptosis, and might play a vital role in the prevention of tumorigenesis [88]. Furthermore, a team led by Zhao MuJun (major inventor) applied for and received a patent for LRTM4 protein, a liver regeneration-associated protein that could be used to repair liver injuries [89]. This team also received patents for the novel human liver cancer-associated suppressor genes LPTS [90] and HCRPI [91].

Researchers at the Second Military Medical University of the People's Liberation Army performed large-scale EST sequencing and analysis on bone marrow stromal cells and dendritic cells. A large number of functional genes related 
to the immune system were cloned and some of them are described here. Hsp $70 L 1$ encodes a heat shock protein that can activate dendritic cells; it was suggested that the Hsp70L1 antigen peptide hybrid may serve as a more effective vaccine for the control of cancer and infectious diseases [16]. KLRL1 is a novel inhibitory natural killer (NK) cell receptor that may play an important role in the regulation of NK-mediated cytotoxicity [17]. SLAMF9 may be involved in the immune response [92]. CXCL14 [93] encodes a novel CXC chemokine macrophage inflammatory protein-2 gamma chemoattractant for human neutrophils and dendritic cells. Siglec-10 [94], DPK [95] and DPZF [96] were cloned from dendritic cells; Siglec-10 might be involved in cell-cell recognition in specific cell populations and $D P K$ that encodes a new dendritic cell-derived protein kinase was reported to participate in signal transduction. $D P K$ was able to activate both the ERK1/ERK2 and SAPK pathways in a dose-dependent manner, but it had no effect on the p38 pathway. DPZF (which shares homology with $B C L-6$ ) encodes the BTB/POZ zinc finger protein transcription factor and is thought to take part in hematopoiesis, oncogenesis and immune responses. Additionally, human CaMKIINalpha [97] and IPP5 [98] were cloned from bone marrow stromal cells. CaMKIINalpha encodes a novel endogenous human CaMKII (calcium dependent protein kinase) inhibitory protein that can suppress tumor growth by inducing cell cycle arrest via p27 stabilization. IPP5 encodes an inhibitory protein of PPI (protein phosphatase 1) that can promote tumor cell growth and cell cycle progression; this gene may be a promising target in cancer therapeutics in IPP5-highly expressing tumor cells. BTBD10 was screened from a human fetal brain cDNA library and cDNA microarray analysis showed that BTBD10 was down-regulated in glioma cells and its expression was different in various grades of glioma [99]. Another gene, NBEAL1 [100], was found to be highly expressed in the biopsies of different grade glioma, especially in lower grade tissue samples; therefore, it was suggested that NBEAL1 might be correlative with glioma. In addition, a team led by Cao XueTao (major inventor) received 14 patents for new human genes that included the genes that encode the cytokine IFL protein and the macrophage inflammatory protein (MIP)- $2 \gamma$. It was proposed that the IFL protein could be used to treat various diseases such as viral infection, tumor, and immune hypofunction [101] while, the new chemokine, MIP- $2 \gamma$ could be used to treat a large number of diseases such as neutropenia or hypofunction of neutrophils, tumors, and autoimmune disease [102].

At the Human Disease Genomic Research Center of Peking University, researchers cloned and identified a series of cytokine and cellular apoptosis-associated genes. For example, $C K L F$ is a chemokine-like factor that plays an important role in inflammation and in the regeneration of skeletal muscle [103] and CKLFSF1-CKLFSF8 are eight genes that encode chemokine-like factor superfamily members 1-8 [104]. When the TFAR19 gene from TF-1 cells undergoing apoptosis was over-expressed in tumor cells, it enhanced apoptosis triggered by growth factor or serum deprivation; therefore, it was proposed that TFAR19 may play a general role in the apoptotic process [23]. AMID encodes an apoptosis-inducing factor-homologous mitochondrion-associated protein that induces caspase-independent apoptosis [105]. Researchers at the center also discovered a series of genes associated with immune response. For example, SIKE1 encodes a physiological suppressor of IKKepsilon and $T B K 1$ encodes a protein that plays an inhibitory role in virus- and TLR3-triggered IRF-3 but not NF-kappaB activation pathways [20]. RNF216 [106] and SINK [107] encode proteins that have similar functions; both proteins are inhibitors of the NF-kappa B activation pathway. Furthermore, $p 42.3$ was reported to be specifically expressed in GC (gastric cancer) tumors and not in normal gastric mucosa and the protein that it encodes was associated with M-phase regulation. Moreover, $p 42.3$ might be involved in cell proliferation and tumorigenesis; therefore, this gene is thought to have potential applications in the diagnosis or treatment of GC [108]. Moreover, a group led by Ma DaLong received various patents including the chemokine-like factor superfamily that can stimulate the activity of skeletal muscle and have an immunomodulatory effect [109], chemokine-like factor CKLF1 with cellular chemotactic and hematopoiesis-stimulating effects [110], and cytokine CKLF-H1A [111] with hematopoiesis-stimulating and immunomodulation effects.

At the Peking University Health Science Center, researchers performed the large-scale identification of human hepatocellular carcinoma-associated antigens using serological analysis of recombinant cDNA expression libraries (SEREX). Their experimental results on tumor Ags in HCC provided candidates for immunological applications and revealed molecular features that may help in understanding tumorigenicity [112]. In addition, SIP that encodes a novel ankyrin repeat containing protein that sequesters steroid receptor coactivators (SRCs) in the cytoplasm and buffers the availability of these coactivators was identified; thus, providing a possible mechanism for the regulation of the transcription regulators [21]. ZIP [113] encodes a novel transcription repressor that is a potential tumor suppressor. Further, some of the experimental findings that have been reported may shed new light on the EGFR-related breast carcinogenesis and might offer a new potential target for breast cancer therapy. FAM83A, a novel human tumor-specific gene, has potential as a biomarker of lung cancer [114] and LAPTM4B [115] is a potential protooncogene whose over-expression is involved in carcinogenesis and the progression of HCC. In normal cells, LAPTM4B may also play important roles in, for example, the regulation of cell proliferation and survival.

Researchers at the Institute of Basic Medical Sciences, Chinese Academy of Medical Sciences have cloned a large number of spermatogenesis-related genes; for example, 
SPATA7 that encodes a meiotic-related protein expressed in rat and human testis [116]; $Z Y X$ that encodes a protein that is linked to sperm maturation and capacitation [117]; $V C X / Y$ that encodes a protein that might participate in regulating the assembly of ribosomes during spermatogenesis [118]; $R G P D 5$ whose mRNA is expressed only in germ cells at all stages of spermatogenesis and is closely associated with spermatogenesis [119]; and $B S-63$ that encodes a protein that acts as a carrier system in transporting aF10 into the nucleus of germ cells during spermiogenesis [120]. Genes related to the genesis of esophageal cancer have also been cloned at the institute. When esophageal squamous cell carcinoma tissue was compared with normal tissue using a cDNA microarray, it was found that the overexpression of EC97 might be associated with the onset of esophageal cancer [121]. Further, the over-expression of RPL15 in esophageal cancer was shown to play a possible role in carcinogenesis of esophagus [122] and SPINK7 might reduce the function of MT2A in the regulation of cell proliferation and in the induction of apoptosis. The direct interaction of SPINK7 and MT2A may play an important role in the carcinogenesis of esophageal cancer [123] and high methylation of the C2orf40 gene might be one of the causes of esophageal cancer [124]. In addition, patents for several esophageal cancer-related genes like NMES1 [125], ECRG-2 [126], DRC1 [127] and DRC2 [128], were issued to the Chinese Academy of Medical Sciences. Furthermore, the gene $O L C 1$ [12] showed a high expression level in primary pulmonary squamous cell carcinoma that, when exposed to cigarette smoke, increased remarkably. This observation led to the suggestion that $O L C 1$ expression is closely connected with smoking history. In addition, $O L C 1$ can activate the NF-kappaB signal transduction pathway and its over-expression can induce evident transformed colony in mouse fibroblastic NIH/3T3 cells, suggesting that this gene is a new candidate oncogene. $H A P O$ encodes a novel human growth factor for the primitive cells of both hematopoietic and endothelial cell lineages that has the potential to be of use in the clinical treatment of various cytopenias and radiation injuries and in the expansion of hematopoietic and endothelial stem/progenitor cells [18]. RNF13 [129] encodes a novel E3 ubiquitin ligase that is involved in pancreatic carcinogenesis. The $H Z F l$ gene [130] plays an important role in erythroid and megakaryocytic differentiation. RHBDD1 [131] encodes a protein that can act as a serine protease that participates in the cleavage of BIK, a proapoptotic member of the Bcl-2 family, and modulates BIK-mediated apoptotic activity. The gene MAN2C1 obtained from the human tonsil cell cDNA library encodes an important cellular alpha-mannosidase [132].

At the Institute of Radiation Medicine, Academy of Military Medical Sciences of People's Liberation Army, researchers have identified a large number of new genes in the human fetal liver transcriptome. For example, Apak encodes a Krüppel-associated box (KRAB)-type zinc-finger protein
[11] that binds directly to p53 in unstressed cells, specifically downregulates pro-apoptotic genes, and suppresses p53-mediated apoptosis. Ceap-11 and Ceap-16 encode two novel splicing variant proteins that are associated with the centrosome, microtubule aggregation and cell proliferation [133]. The proteins encoded by SEMA6C and SEMA6D belong to the transmembrane semaphorin family and may play important roles in nerve regeneration [134]. $N G B$ is a highly conserved gene and the protein that it encodes plays an important role in the nervous system, possibly related to oxygen supply to the neuron [135]. CKIP-1 encodes a c-Jun-interacting protein that regulates AP-1 activity via caspase-3-dependent cleavage and translocation [136]. $P A C T$, which encodes a ring finger-containing protein, is highly up-regulated in esophageal cancer. Experimental data has shown that the PACT-p53 interaction plays a crucial role in embryonic development and tumorigenesis and the PACT protein has been identified as one of the negative regulators of $\mathrm{p} 53$ [137]. ARFGAP1 encodes a GATA-1 zinc finger-containing protein that might take part in the process of reproduction [138]. The CUEDC2-encoded protein interacts with the progesterone receptor (PR) and promotes progesterone-induced PR degradation through the ubiquitinproteasome pathway. Furthermore, an important posttranslational mechanism that controls PR protein levels was identified which, for the first time, provided an important insight into the function of CUEDC2 in breast cancer proliferation [139].

Researchers at the Nanjing Medical University detected differential expressed genes in testis using a cDNA microarray and a substantial set of genes associated with testicular development and spermatogenesis were obtained. For example, TPD52L3 that encodes a new member of the tumor protein D52-like proteins family was found to be expressed in adult testis at levels that were 5.6-fold higher than in fetal testis. The expression profile also showed that TPD52L3 is testis-specific, indicating thatTPD52L3 may play a role in testis development and spermatogenesis [140]. SPATA16 is involved in spermatogenesis and the SPATA16encoded protein might function in the Golgi apparatus [141]. CCDC65 is highly expressed in human testis and spermatozoa, and the protein it encodes is a new human sperm tail protein that might play an important role during sperm capacitation [142]. Other genes like LDHL6B [143], NYD-SP5 [144], ACSBG2 [145], PHF7 [146], and SPATA9 [147] are all believed to be closely associated with testicular development and spermatogenesis.

At the Cancer Research Institute, Central South University, Changsha, a series of genes related to the genesis of nasopharyngeal carcinoma (NPC) were cloned and identified. For example, CCDC19 may be a tissue-specific gene in columnar ciliated epithelium and might be linked to the onset of NPC [148]. In the NPC cell line HNE1, the expression of C1orf102 was down-regulated, and the Glu58Gly polymorphism that the encoded protein contains may be 
involved in the development and/or progression of NPC suggesting that Clorf102 could be a candidate tumor repressor gene related with NPC [149]. GGNBP2 is localized in the tumor suppressor locus D17S800-D17S930 and may be correlated with the genesis of laryngeal carcinoma [150]. In addition, NAG6 is significantly down-regulated in gastric cancer; it was proposed that the loss of genetic material may be the cause of down-regulation of NAG6 expression. If this is the case, then NAG6 could be a candidate of putative tumor suppressor gene at the 7q31-32 loci associated with gastric carcinoma. The down-regulation of NAG6 may play a role in the occurrence and development of gastric cancer; however, it may not be associated with lymph node and/or distance metastasis [151]. LRRC4 shows increased expression in brain tumor tissue, suggesting that this gene may play an important role in maintaining normal function and suppressing tumorigenesis in the central nervous system [152]. SPATA12 was found to control cellular differentiation and inhibit cellular proliferation in human testicular tissue and it may play a role in spermatogenesis [153]. In addition, TSARG2 [154] and DNAJB13 [155], two genes that are related to the apoptosis of spermatocyte, have been reported.

Researchers at the Center for Heart Development, Hunan Normal University, established a human embryo heart cDNA library and cloned a large number of development-related genes. Many of these genes encode proteins that belong to the zinc finger protein family; they include, ZNF641 [156], ZNF415 [157], ZNF12 [158], ZNF569 [159], ZNF540 [160], ZNF446 [161], and ZNF649 [162]. The proteins that these genes encode mainly participate in the development of the heart by regulating the transcription activity of AP-1, SRE and other proteins in the MAPK signaling pathway.

Gene cloning and identification was started early in Hong Kong and Taiwan. Although only a few human functional genes were discovered, many high-quality studies have been published; 17 of the papers $(26.98 \%)$ have been cited over 20 times, and 18 papers $(28.57 \%)$ were published in journals with IFs over 5. The NYD-SP27 [10] gene was studied by researchers at the Chinese University of Hong Kong and in 2003 a report was published in Lancet $(\mathrm{IF}=33.633)$; so far this is the highest-IF journal to publish a paper on a human functional gene that was first cloned and identified by Chinese scientists. NYD-SP27 is expressed endogenously in human pancreatic-duct cells and upregulated in cystic fibrosis. The NYD-SP27 protein exerts an inhibitory effect on phospholipase-C-coupled processes that depend on calcium ions and protein kinase $\mathrm{C}$, including CFTR trafficking and function. Its upregulation in pancreatic-duct cells may reveal a previously unsuspected defect in cystic fibrosis that contributes to pancreatic insufficiency; thus, NYD-SP27 was proposed as a potentially new target for pharmacological intervention in cystic fibrosis. Researchers at the Taiwan Chang Gung Medical College iden- tified $P N N$ [163], a gene that is associated with the mature desmosomes of the epithelia. At the Institute of Biomedical Sciences, Academia Sinica, Taiwan, RBM4B [164] that encodes a novel splicing regulator was discovered. At the Institute of Life Science, National Defense Medical College, Academia Sinica, Taiwan, researchers identified CENPJ that is believed to play an essential role in cell division and centrosome function [165]. Scientists from the Taiwan National Yang-Ming University discovered NOLC1 that is associated with nucleogenesis during mitosis [166]. EEN was discovered by researchers from the department of $\mathrm{Pa}$ thology at the University of Hong Kong on the short arm of chromosome 19; the fusion of the EEN gene with the chromosome translocation $M L L$ gene was found to cause acute myeloid leukemia [167]. SH3D19 encodes a novel EENbinding protein that can inhibit Ras signaling and that is recruited into the nucleus by the MLL-EEN fusion protein that is believed to play an important role in the onset of leukemia [168]. Furthermore, scientists from the Hong Kong Polytechnic University discovered a candidate oncogene gene $F A M 134 B$ on the short arm of human chromosome 5 whose overexpression and transforming capacity in normal cells may play a critical role in the molecular pathogenesis of esophageal squamous cell carcinoma (ESCC) [169].

The Chinese contribution to the cloning and identification of human functional genes actually reflects the development of the life sciences in China. From initial gene sequencing and mapping to the establishment of cDNA libraries and large-scale cDNA sequencing, and then to functional studies on single genes at the molecular, cellular and animal levels; and from low IF journals to world-leading journals, the studies in life sciences in China have progressed from weak to strong, and continue to stride forward.

In terms of the number of genes that were first cloned and identified by Chinese scientists, whether the total number of genes is taken to be the 40000 estimated by the HGP for reference, or the 30000 estimated protein-encoding genes, or the 17000 that have been cloned and identified for reference, the 589 cloned genes and 159 patents achieved by Chinese scientists fulfill the "two 1\%" goal that was proposed by the Committee of Experts in Biology of the 863 Program. This achievement represents another of China's significant contributions to the study of human genomics after its earlier " $1 \%$ " sequencing work.

However, some limitations in the Chinese studies on human functional genes should be noted. Most of the cloned and identified genes are not important ones, and the majority of studies have been focused only on gene sequencing, localization and expression profiles. Because these studies lack depth, most papers were rarely cited. Further, most of the new gene patents were awarded to teams based in colleges and universities rather than from enterprises. The funds for scientific research mostly come from state appropriations and not from investment by enterprises; this results 
in the inadequate commercialization of research findings and makes it almost impossible to generate huge economic value and good society benefits. In the future, scientists working in China should perform in-depth studies on human functional genomics to discover functionally important new genes. Such a focus will help propel the practical application of new research findings to make greater contributions to the development of Chinese biomedicine and the health of the population.

It is possible that some errors will exist in the 544 papers and 159 issued patents that were retrieved and analyzed in this study. We will monitor this and regularly update our literature database (http://gene.fudan.sh.cn/introduction/ database/chinagene/chinagene.html). We welcome any valuable advice, comments and corrections.

This work was supported by the Foundation for Innovative Research Groups of the National Natural Science Foundation of China (Grant No. 30024001), the National Basic Research Program of China (Grant No. 2004CB518605), the Major National Science and Technology Program of China (Grant No. 2008ZX10002-020), and the National High Technology Research and Development Program of China (Grant Nos. 2006AA020501 and 2001AA221081). This paper is dedicated to Mr. Tan JiaZhen, a pioneer in Chinese genetics who made outstanding contributions to the initiation and development of human functional genomics in China.

1 Robertso H D, Barrell B G, Weith H L, et al. Isolation and sequence analysis of a ribosome-protected fragment from bacteriophage phi-X 174 DNA. Nat New Biol, 1973, 241: 38-40

2 Ziff E B, Sedat J W, Galibert F. Determination of the nucleotide sequence of a fragment of bacteriophage phi-X 174 DNA. Nat New Biol, 1973, 241: 34-37

3 Sanger F, Air G M, Barrell B G, et al. Nucleotide sequence of bacteriophage phi-X 174 DNA. Nature, 1977, 265: 687-695

4 Gibbs R A, Belmont J W, Hardenbol P, et al. The International HapMap Project. Nature, 2003, 426: 789-796

5 Martial J A, Hallewell R A, Baxter J D, et al. Human growth hormone: complementary DNA cloning and expression in bacteria. Science, 1979, 205: 602-607

6 Blattner F R, Blechl A E, Denniston T K, et al. Cloning human fetal gamma globin and mouse alpha-type globin DNA: preparation and screening of shotgun collections. Science, 1978, 202: 12791284

7 Chang C Y, Wu D A, Mohandas T K, et al. Structure, sequence, chromosomal location, and evolution of the human ferredoxin gene family. DNA Cell Biol, 1990, 9: 205-212

8 Zhang M L, Wang L F, Miao S Y, et al. Isolation and sequencing of the cDNA encoding the $75-\mathrm{kD}$ human sperm protein related to infertility. Chin Med J (Engl), 1992, 105: 998-1003

9 Lander E S, Linton L M, Birren B, et al. International Human Genome Sequencing Consortium. Initial sequencing and analysis of the human genome. Nature, 2001, 409: 860-921

10 Zhu H, Zhu J X, Lo P S, et al. Rescue of defective pancreatic secretion in cystic-fibrosis cells by suppression of a novel isoform of phospholipase C. Lancet, 2003, 362: 2059-2065

11 Tian C, Xing G, He F, et al. KRAB-type zinc-finger protein Apak specifically regulates p53-dependent apoptosis. Nat Cell Biol, 2009, 11: 580-591

12 Yuan J, Ma J, Ma D, et al. Overexpression of OLC1, cigarette smoke, and human lung tumorigenesis. J Natl Cancer Inst, 2008, 100: $1592-1605$

13 Liao C, Zhao M, Song H, et al. Identification of the gene for a novel liver-related putative tumor suppressor at a high-frequency loss of heterozygosity region of chromosome 8p23 in human hepatocellular carcinoma. Hepatology, 2000, 32: 721-727

14 Xu Z G, Du J J, Han Z G, et al. A novel liver-specific zona pellucida domain containing protein that is expressed rarely in hepatocellular carcinoma. Hepatology, 2003, 38: 735-744

15 Ma N F, Hu L, Fung J M, et al. Isolation and characterization of a novel oncogene, amplified in liver cancer 1, within a commonly amplified region at 1q21 in hepatocellular carcinoma. Hepatology, 2008, 47: 503-510

16 Wan T, Zhou X, Cao X, et al. Novel heat shock protein Hsp70L1 activates dendritic cells and acts as a Th1 polarizing adjuvant. Blood, 2004, 103: 1747-1754

17 Han Y, Zhang M, Cao X, et al. KLRL1, a novel killer cell lectinlike receptor, inhibits natural killer cell cytotoxicity. Blood, 2004, 104: 2858-2866

18 Liu Y J, Lu S H, Han Z C, et al. Hemangiopoietin, a novel human growth factor for the primitive cells of both hematopoietic and endothelial cell lineages. Blood, 2004, 103: 4449-4456

19 Chen Z, Brand N J, Chen A, et al. Fusion between a novel Krüppel-like zinc finger gene and the retinoic acid receptor-alpha locus due to a variant $\mathrm{t}(11 ; 17)$ translocation associated with acute promyelocytic leukaemia. EMBO J, 1993, 12: 1161-1167

20 Huang J, Liu T, Shu $\mathrm{H}$ B, et al. SIKE is an IKK epsilon/TBK1-associated suppressor of TLR3- and virus-triggered IRF-3 activation pathways. EMBO J, 2005 , 24: 4018-4028

21 Zhang Y, Zhang H, Shang Y, et al. SIP, a novel ankyrin repeat containing protein, sequesters steroid receptor coactivators in the cytoplasm. EMBO J, 2007, 26: 2645-2657

22 Qu X, Zhai Y, He F, et al. Characterization and expression of three novel differentiation-related genes belong to the human NDRG gene family. Mol Cell Biochem, 2002, 229: 35-44

23 Liu H T, Wang Y G, Zhang Y M, et al. TFAR19, a novel apoptosis-related gene cloned from human leukemia cell line TF-1, could enhance apoptosis of some tumor cells induced by growth factor withdrawal. Biochem Biophys Res Commun, 1999, 254: 203210

24 Carbon S, Ireland A, Mungall C J, et al. AmiGO: online access to ontology and annotation data. Bioinformatics, 2009, 25: 288-289

25 Mao Y M, Xie Y. Polypeptide-human actin-binding protein 54 and a polynucleotide encoding the same. US Patent, 7273724, 200105-31

26 Mao Y M, Xie Y. Polypeptide-phosphatidic acid phosphatase 29.81 and the polynucleotide encoding said polypeptide. US Patent, 7056719, 2002-04-04

27 Mao Y M, Xie Y. Polypeptide human polyadenylation binding protein 20.13 and polynucleotide encoding it. US Patent, 7049404, 2002-04-04

28 Mao Y M, Xie Y. Polypeptide, human vacuolar H.sup. ${ }^{+}$-ATPase C subunit 42 and polynucleotide encoding it. US Patent, 6994996, 2001-05-03

29 Mao Y M, Xie Y. Steroid dehydrogenase 34 and the polynucleotide encoding same. US Patent, 6984509, 2001-05-03

30 Mao Y M, Xie Y. Polypeptide-human SNARE protein 25 and a polynucleotide encoding the same. US Patent, 6919431, 200105-31

31 Mao Y M, Xie Y. Polypeptide--human galectin 15 and a polynucleotide encoding the same. US Patent, 6919430, 2001-05-03

32 Mao Y M, Xie Y. Polypeptide-RNA binding protein 33 and polynucleotide encoding said polypeptide. US Patent, 6919427, 200105-03

33 Mao Y M, Xie Y. Polypeptide-human SR splicing factor 52 and a polynucleotide encoding the same. US Patent, 6908765, 200105-31

34 Mao Y M, Xie Y. Polypeptide-calcitonin 11 and the polynucleotide encoding it. US Patent, 6844323, 2001-06-28

35 Mao Y M, Xie Y. Human calcium binding protein and a polynucleotide encoding the same. US Patent, 6811987, 2001-05-31

36 Mao Y M, Sheng X Y, Yuan Y Z, et al. Thermophilic alkaline phosphoesterase and its expression. US Patent, 6649390, 
2001-05-31

37 Yu L, Zhao Y, Hu P R, et al. Human g-type lysozyme, the encoding sequence, preparing method and the uses thereof. US Patent, 6943244, 2002-09-12

38 Yu L, Zhao Y, Zhang H L, et al. DNA encoding a new human hepatoma derived growth factor and producing method thereof. US Patent, 6893844, 2000-03-30

39 Yu L, Zhao Y, Zhang H L, et al. Human lysozyme gene, its encoded polypeptide and the method for preparing them. US Patent, 6743617, 2000-03-09

40 Yu L, Zhao Y, Zhang H L, et al. Human lysozyme gene, it's encoded polypeptide and the method of preparing them. US Patent, 6660512, 2000-03-09

$41 \mathrm{Yu}$ L, Fu Q, Hu P R, et al. Human growth differentiation factor encoding sequence and polypeptide encoded by such DNA sequence and producing method thereof. US Patent, 6656708, 2000-03-30

42 Yu L, Zhao Y, Hu P R, et al. Human lysozyme gene, its encoded polypeptide and the method for preparing them. US Patent, 6528297 , 2001-03-09

43 Yu L, Zhao Y, Hu P R, et al. Human lysozyme gene, its encoding polypeptide and the method preparing for them. US Patent, 6436688, 2000-03-09

44 Zhao X T, Wan D F, Gu J R. Human hepatoma associated protein and the polynucleotide encoding said polypeptide. US Patent, 7112419, 2001-11-15

45 Gu J R, Yang S L. Human longevity assurance protein, its coding sequence and their use. US Patent, 7037683, 2003-03-14

46 Ma D L, Han W L, Huang J Q, et al. Nucleic acid molecule encoding chemokine-like factor 1 (CKLF1). US Patent, 6800454, 200103-07

47 Ma D L, Han W L, Huang J Q, et al. Chemokine-like factors (CKLFs) with chemotactic and hematopoietic stimulating activities. US Patent, 7365171, 2004-06-02

48 Zhao M J, Liu Z W, Qiu J, et al. Human liver regeneration associated protein and the use thereof. US Patent, 7741468, 2004-07-22

49 Xiong S Q, Chang Z J. Polynucleotide encoding human interleukin-17 receptor like molecule. US Patent, 7141390, 2003-06-30

$50 \mathrm{Yu}$ L, Zhang H L, Fu Q, et al. New human growth differentiation factor encoding sequence and polypeptide encoded by such DNA sequence and producing method thereof. EP Patent, 1116792, 2007-01-24

51 Yu L, Zhang H L, Fu Q, et al. A novel human lysozyme gene, its encoding polypeptide and the method preparing for them. EP Patent, 1111059, 2009-07-01

52 Yu L, Zhang H L, Fu Q, et al. A new gene of human lysoenzyme, the encoding polypeptide and methods for preparing them. EP Patent, 1111054, 2009-06-27

53 Yu L, Zhang H L, Fu Q, et al. New human hepatoma-derived growth factor encoding sequence and polypeptide encoded by such DNA sequence and producing method thereof. CA Patent, 2343719, 2000-03-30

$54 \mathrm{Yu}$ L, Zhang H L, Fu Q, et al. New human growth differentiation factor encoding sequence and polypeptide encoded by such DNA sequence and producing method thereof. CA Patent, 2343715, 2000-03-30

$55 \mathrm{Hu} \mathrm{Q} \mathrm{D}, \mathrm{Lu} \mathrm{H}, \mathrm{Li} \mathrm{Y} \mathrm{Y,} \mathrm{et} \mathrm{al.} \mathrm{A} \mathrm{human} \mathrm{homolog} \mathrm{of} \mathrm{the} \mathrm{yeast}$ gene encoding tRNA 2'-phosphotransferase: cloning, characterization and complementation analysis. Cell Mol Life Sci, 2003, 60: 1725-1732

56 Lin S, McLennan A G, Mao Y, et al. Cloning, expression, and characterization of a human inosine triphosphate pyrophosphatase encoded by the itpa gene. J Biol Chem, 2001, 276: 18695-18701

57 Zheng L, Yu L, Tu Q, et al. Cloning and mapping of human PKIB and PKIG, and comparison of tissue expression patterns of three members of the protein kinase inhibitor family, including PKIA. Biochem J, 2000, 349: 403-407

58 Tu Q, Yu L, Zhang P, et al. Cloning, characterization and mapping of the human ATP5E gene, identification of pseudogene ATP5EP1, and definition of the ATP5E motif. Biochem J, 2000, 347: 17-21
59 Chen J, Yu L, Li D, et al. Human CRYL1, a novel enzyme-crystallin overexpressed in liver and kidney and downregulated in $58 \%$ of liver cancer tissues from 60 Chinese patients, and four new homologs from other mammalians. Gene, 2003, 302: 103-113

$60 \mathrm{He} \mathrm{H}$, Dai F, Yu L, et al. Identification and characterization of nine novel human small GTPases showing variable expression in liver cancer tissues. Gene Expr, 2002, 10: 231-242

$61 \mathrm{Wu}$ X, Jia H L, Wang Y F, et al. HTPAP gene on chromosome 8p is a candidate metastasis suppressor for human hepatocellular carcinoma. Oncogene, 2006, 25: 1832-1840

$62 \mathrm{He}$ H, Dang Y J, Dai F Y, et al. Post-translational modifications of three members of the human MAP1LC3 family and detection of a novel type of modification for MAP1LC3B. J Biol Chem, 2003, 278: 29278-29287

$63 \mathrm{Xu} \mathrm{J}, \mathrm{He} \mathrm{T}$, Wang L, et al. Molecular cloning and characterization of a novel human BTBD8 gene containing double BTB/POZ domains. Int J Mol Med, 2004, 13: 193-197

64 Zhang Z, Wu C, Huang W, et al. A novel human gene whose product shares homology with bovine brain-specific protein p25 is expressed in fetal brain but not in adult brain. J Hum Genet, 2002, 47: 266-268

65 Zou X Q, Wang D Z, Qiu G Z, et al. Molecular cloning and characterization of a novel human C4orf13 gene, tentatively a member of the sodium bile acid cotransporter family. Biochem Genet, 2005, 43: $165-173$

66 Ye X, Ji C, Yin G, et al. Characterization of a human Sec14-like protein cDNA SEC14L3 highly homologous to human SPF/TAP. Mol Biol Rep, 2004, 31: 59-63

67 Zhou G J, Wang J, Zhang Y, et al. Cloning, expression and subcellular localization of HN1 and HN1L genes, as well as characterization of their orthologs, defining an evolutionarily conserved gene family. Gene, 2004, 331: 115-123

68 Liu L L, Zhang J X, Yuan J, et al. Characterization of a human regulatory subunit of protein phosphatase 3 gene (PPP3RL) expressed specifically in testis. Mol Biol Rep, 2005, 32: 41-45

69 Zhao W, Tang R, Huang Y, et al. Cloning and expression pattern of the human NDRG3 gene. Biochim Biophys Acta , 2001, 1519: 134-138

$70 \mathrm{Yu}$ L, Fu Q, Zhao Y, et al. A novel human lysozyme gene, its encoding polypeptide and the method preparing for them. CN Patent, 99810036, 1999-08-30

71 Yu L, Fu Q, Zhao Y, et al. A novel human lysozyme gene, its encoding polypeptide and the method preparing for them. CN Patent, 99810037, 1999-08-30

72 Yu L, Fu Q, Zhao Y, et al. A novel human lysozyme gene, its encoding polypeptide and the method preparing for them. CN Patent, 99810038, 1999-08-30

$73 \mathrm{Yu} \mathrm{L}, \mathrm{Fu} \mathrm{Q}$, Zhao Y, et al. A human UMP/CMP kinase, its coding sequence, method for making and its use. CN Patent, 99102449, 1999-02-26

74 Yu M, Tong J H, Mao M, et al. Cloning of a gene (RIG-G) associated with retinoic acid-induced differentiation of acute promyelocytic leukemia cells and representing a new member of a family of interferon-stimulated genes. Proc Natl Acad Sci USA, 1997, 94: 7406-7411

75 Mao M, Yu M, Tong J H, et al. RIG-E, a human homolog of the murine Ly-6 family, is induced by retinoic acid during the differentiation of acute promyelocytic leukemia cell. Proc Natl Acad Sci USA, 1996, 93: 5910-5914

$76 \mathrm{Xu} \mathrm{J,} \mathrm{Ni} \mathrm{M,} \mathrm{Wan} \mathrm{F,} \mathrm{et} \mathrm{al.} \mathrm{The} \mathrm{ATF/CREB} \mathrm{site} \mathrm{is} \mathrm{the} \mathrm{key} \mathrm{element} \mathrm{for}$ transcription of the human RNA methyltransferase like 1(RNMTL1) gene, a newly discovered $17 \mathrm{p} 13.3$ gene. Cell Res, 2002, 12: 177-197

77 Qin W X, Wan F, Sun F Y, et al. Cloning and characterization of a novel gene (C17orf25) from the deletion region on chromosome 17p13.3 in hepatocelular carcinoma. Cell Res, 2001, 11: 209-216

78 Zhao X, Li J, Gu J, et al. A novel growth suppressor gene on chromosome $17 \mathrm{p} 13.3$ with a high frequency of mutation in human hepatocellular carcinoma. Cancer Res, 2001, 61: 7383-7387 
79 Wan D F, Gu J R, Yang S L. A tumor-associated secreted protein as a liver cancer marker and its use. CN Patent, 200310109398, 2003-12-15

$80 \mathrm{Gu} \mathrm{J}$ R,Wan D F. A tumor-associated secreted protein as a liver cancer marker and its use. CN Patent, 200310109301, 2003-12-12

81 Gu J R, Yang S L, Qin W X. A pro-apoptotic gene BNIPL, its encoded protein and its use. CN Patent, 02151030, 2002-12-04

82 Han Z G, Zhang Q H, Chen Z, et al. Molecular cloning of six novel Krüppel-like zinc finger genes from hematopoietic cells and identification of a novel transregulatory domain KRNB. J Biol Chem, 1999, 274: 35741-35748

83 Pan W, Zhang Q, Xi Q S, et al. FUP1, a gene associated with hepatocellular carcinoma, stimulates NIH3T3 cell proliferation and tumor formation in nude mice. Biochem Biophys Res Commun, 2001, 286: 1033-1038

84 Huang R, Xing Z, Luan Z, et al. A specific splicing variant of SVH, a novel human armadillo repeat protein, is up-regulated in hepatocellular carcinomas. Cancer Res, 2003, 63: 3775-3782

$85 \mathrm{Xu} \mathrm{Z}$, Liang L, Wang $\mathrm{H}$, et al. HCRP1, a novel gene that is downregulated in hepatocellular carcinoma, encodes a growthinhibitory protein. Biochem Biophys Res Commun, 2003, 311: 1057-1066

86 Liu Q, Hamil K G, Rao A J, et al. Characterization of ESC42, a novel protein containing a trefoil-like motif in monkey and human. Endocrinology , 2001, 142: 4529-4539

87 Zhang D H, Zhou B, Huang Y, et al. The human Pif1 helicase, a potential Escherichia coli RecD homologue, inhibits telomerase activity. Nucleic Acids Res, 2006, 34: 1393-1404

88 Liang L, Zhao M, Xu Z, et al. Molecular cloning and characterization of CIDE-3, a novel member of the cell-death-inducing DNA-fragmentation-factor (DFF45)-like effector family. Biochem J, 2003, 370: 195-203

89 Zhao M J, Liu Z W, Li Z P. Human liver regeneration associated protein and the use thereof. CN Patent, 01105282, 2001-01-22

90 Zhao M J, Liao C, Li Z P. A liver cancer-related gene and its application. CN Patent, 00115395, 2000-04-14

91 Zhao M J, Xu Z H, Liang L, et al. A tumor suppressor protein and its application. CN Patent, 03116920, 2003-05-14

92 Zhang W, Wan T, Li N, et al. Genetic approach to insight into the immunobiology of human dendritic cells and identification of CD84-H1, a novel CD84 homologue. Clin Cancer Res, 2001, 7: $822 \mathrm{~s}-829 \mathrm{~s}$

93 Cao X, Zhang W, Wan T, et al. Molecular cloning and characterization of a novel CXC chemokine macrophage inflammatory protein-2 gamma chemoattractant for human neutrophils and dendritic cells. J Immunol, 2000, 165: 2588-2595

94 Li N, Zhang W, Wan T, et al. Cloning and characterization of Siglec-10, a novel sialic acid binding member of the Ig superfamily, from human dendritic cells. J Biol Chem, 2001, 276: 28106-28112

95 Zhang W, Chen T, Cao X, et al. Cloning of DPK, a novel dendritic cell-derived protein kinase activating the ERK1/ERK2 and JNK/SAPK pathways. Biochem Biophys Res Commun, 2000, 274: 872-879

96 Zhang W, Mi J, Cao X, et al. Identification and characterization of DPZF, a novel human BTB/POZ zinc finger protein sharing homology to BCL-6. Biochem Biophys Res Commun, 2001, 282: 10671073

97 Wang C, Li N, Cao X, et al. A novel endogenous human CaMKII inhibitory protein suppresses tumor growth by inducing cell cycle arrest via p27 stabilization. J Biol Chem, 2008, 283: 11565-11574

98 Wang X, Liu B, Cao X, et al. IPP5, a novel protein inhibitor of protein phosphatase 1 , promotes $\mathrm{G} 1 / \mathrm{S}$ progression in a Thr-40dependent manner. J Biol Chem, 2008, 283: 12076-12084

99 Chen J, Xu J, Ying K, et al. Molecular cloning and characterization of a novel human BTB domain-containing gene, BTBD10, which is down-regulated in glioma. Gene, 2004, 340: 61-69

100 Chen J, Lu Y, Xu J, et al. Identification and characterization of NBEAL1, a novel human neurobeachin-like 1 protein gene from fetal brain, which is up regulated in glioma. Brain Res Mol Brain Res,
2004, 125: 147-155

101 Cao X T, Zhang W P, Wan T, et al. A interferon-like protein, its coding sequence and its use. CN Patent, 99124272, 1999-12-16

102 Cao X T, Zhang W P, Wan T, et al. A novel human chemokine macrophage inflammatory protein, its coding sequence and its use. CN Patent, 99127033, 1999-12-29

103 Han W, Lou Y, Tang J, et al. Molecular cloning and characterization of chemokine- like factor 1 (CKLF), a novel human cytokine with unique structure and potential chemotactic activity. Biochem $\mathrm{J}$, 2001, 357: 127-135

104 Han W, Ding P, Xu M, et al. Identification of eight genes encoding chemokine-like factor superfamily members 1-8 (CKLFSF1-8) by in silico cloning and experimental validation. Genomics, 2003, 81: 609-617

$105 \mathrm{Wu} \mathrm{M}, \mathrm{Xu} \mathrm{L} \mathrm{G,} \mathrm{Shu} \mathrm{H} \mathrm{B,} \mathrm{et} \mathrm{al.} \mathrm{AMID,} \mathrm{an} \mathrm{apoptosis-inducing}$ factor-homologous mitochondrion-associated protein, induces caspase-independent apoptosis. J Biol Chem, 2002, 277: 2561725623

106 Chen D, Li X, Shu H B, et al. A novel zinc finger protein interacts with receptor-interacting protein (RIP) and inhibits tumor necrosis factor (TNF)- and IL1-induced NF-kappa B activation. J Biol Chem, 2002, 277: 15985-15991

$107 \mathrm{Wu} \mathrm{M}, \mathrm{Xu} \mathrm{L} \mathrm{G}$, Shu H B, et al. SINK is a p65-interacting negative regulator of NF-kappaB-dependent transcription. J Biol Chem, 2003, 278: 27072-27079

$108 \mathrm{Xu} \mathrm{X,} \mathrm{Li} \mathrm{W,} \mathrm{Fan} \mathrm{X,} \mathrm{et} \mathrm{al.} \mathrm{Identification} \mathrm{and} \mathrm{characterization} \mathrm{of} \mathrm{a}$ novel p42.3 gene as tumor-specific and mitosis phase-dependent expression in gastric cancer. Oncogene, 2007, 26: 7371-7379

109 Han W L, Ma D L, Ding P G, et al. The chemokine-like factor superfamily with skeletal muscle stimulating activity and immunomodulatory effects. CN Patent, 02122266, 2002-06-03

110 Ma D L, Han W L, Zhang Y M, et al. Chemokine-like factors (CKLFs) with chemotactic and hematopoietic stimulating activities. CN Patent, 00807234, 2000-02-15

111 Wang L, Ma D L, Han W L, et al. Cytokines of CKLF-H1A with hematopoietic stimulating activities and immunomodulatory effects and its variant of CKLF-H1B. CN Patent, 00121027, 200007-13

112 Wang Y, Han K J, Chen W F, et al. Large scale identification of human hepatocellular carcinoma-associated antigens by autoantibodies. J Immunol, 2002, 169: 1102-1109

113 Li R, Zhang H, Shang Y, et al. ZIP: a novel transcription repressor, represses EGFR oncogene and suppresses breast carcinogenesis. EMBO J, 2009, 28: 2763-2776

114 Li Y, Dong X, Yin Y, et al. BJ-TSA-9, a novel human tumor-specific gene, has potential as a biomarker of lung cancer. Neoplasia, 2005, 7: 1073-1080

115 Shao G Z, Zhou R L, Zhang Q Y, et al. Molecular cloning and characterization of LAPTM4B, a novel gene upregulated in hepatocellular carcinoma. Oncogene, 2003, 22: 5060-5069

116 Zhang X, Liu H, Zhang Y, et al. A novel gene, RSD-3/HSD-3.1, encodes a meiotic-related protein expressed in rat and human testis. J Mol Med (Berl). 2003, 81: 380-387

117 Wang L F, Miao S Y, Zong S D, et al. Gene encoding a mammalian epididymal protein. Biochem Mol Biol Int, 1994, 34: 1131-1136

118 Zou S W, Zhang J C, Wang L F, et al. Expression and localization of $\mathrm{VCX} / \mathrm{Y}$ proteins and their possible involvement in regulation of ribosome assembly during spermatogenesis. Cell Res, 2003, 13: 171-177

119 Wang L F, Zhu H D, Miao S Y, et al. Molecular cloning and characterization of a novel testis-specific nucleoporin-related gene. Arch Androl, 1999, 42: 71-84

120 Cai Y, Gao Y, Sheng Q, et al. Characterization and potential function of a novel testis-specific nucleoporin BS-63. Mol Reprod Dev, 2002, 61: 126-134

121 Lu J, Hu G, Wang X, et al. Cloning and characterization of a novel gene EC97 associated with human esophageal squamous cell carcinoma. Int J Mol Med, 2003, 11: 243-247

122 Wang Q, Yang C, Zhou J, et al. Cloning and characterization of 
full-length human ribosomal protein L15 cDNA which was overexpressed in esophageal cancer. Gene, 2001, 263: 205-209

123 Cui Y, Wang J, Zhang X, et al. ECRG2, a novel candidate of tumor suppressor gene in the esophageal carcinoma, interacts directly with metallothionein 2A and links to apoptosis. Biochem Biophys Res Commun, 2003, 302: 904-915

124 Bi M X, Han W D, Lu S X. Using lab on-line to clone and identify the esophageal cancer related gene 4. Sheng Wu Hua Xue Yu Sheng Wu Wu Li Xue Bao (Shanghai), 2001, 33: 257-261

125 Liu Z H, Zhou J, Ding F, et al. Esophageal cancer-related gene NMES1 and its encoded polypeptide. CN Patent, 02141991, 2002-09-02

126 Lu S X. Esophageal cancer-related gene-2 and its encoded polypeptide. CN Patent, 02143175, 2002-09-16

127 Wang M R, Xu Z X, Cai Y, et al. A novel esophageal cancer-related gene. CN Patent, 99117524, 1999-08-10

128 Wang M R, Xu Z X, Cai Y, et al. A novel esophageal cancer-related gene. CN Patent, 99117523, 1999-08-10

129 Zhang Q, Meng Y, Zhu D, et al. RNF13: a novel RING-type ubiquitin ligase over-expressed in pancreatic cancer. Cell Res, 2009, 19: 348-357

130 Peng H, Du Z W, Zhang J W. Identification and characterization of a novel zinc finger protein (HZF1) gene and its function in erythroid and megakaryocytic differentiation of K562 cells. Leukemia, 2006, 20: $1109-1116$

131 Wang Y, Guan X, Wang L, et al. A novel member of the Rhomboid family, RHBDD1, regulates BIK-mediated apoptosis. Cell Mol Life Sci, 2008, 65: 3822-3829

132 Lin W, Zhou X F, Zhang M L, et al. Cloning, expression and characterization of a cDNA (6A8) encoding a novel human alpha-mannosidase. Eur J Biochem, 2000, 267: 7176-7183

133 Wang Z, Wei H, He F, et al. Characterization of Ceap-11 and Ceap-16, two novel splicing-variant-proteins, associated with centrosome, microtubule aggregation and cell proliferation. J Mol Biol, 2004, 343: 71-82

134 Qu X, Wei H, He F, et al. Identification, characterization, and functional study of the two novel human members of the semaphorin gene family. J Biol Chem, 2002, 277: 35574-35585

135 Zhang C, Wang C, He F, et al. Full-length cDNA cloning of human neuroglobin and tissue expression of rat neuroglobin. Biochem Biophys Res Commun, 2002, 290: 1411-1419

136 Zhang L, Xing G, He F, et al. Role for the pleckstrin homology domain-containing protein CKIP-1 in AP-1 regulation and apoptosis. EMBO J, 2005, 24: 766-778

137 Li L, Deng B, He F, et al. PACT is a negative regulator of p53 and essential for cell growth and embryonic development. Proc Natl Acad Sci USA, 2007, 104: 7951-7956

138 Zhang C, Yu Y, He F, et al. Characterization, chromosomal assignment, and tissue expression of a novel human gene belonging to the ARF GAP family. Genomics, 2000, 63: 400-408

139 Zhang P J, Zhao J, Zhang X M, et al. CUE domain containing 2 regulates degradation of progesterone receptor by ubiquitin-proteasome. EMBO J, 2007, 26: 1831-1842

140 Cao Q, Chen J, Zhu L, et al. A testis-specific and testis developmentally regulated tumor protein D52 (TPD52)-like protein TPD52L3/hD55 interacts with TPD52 family proteins. Biochem Biophys Res Commun, 2006, 344: 798-806

$141 \mathrm{Xu}$ M, Xiao J, Chen J, et al. Identification and characterization of a novel human testis-specific Golgi protein, NYD-SP12. Mol Hum Reprod, 2003, 9: 9-17

142 Zheng Y, Zhang J, Wang L, et al. Cloning and characterization of a novel sperm tail protein, NYD-SP28. Int J Mol Med, 2006, 18: 1119-1125

143 Wang H, Zhou Z, Lu L, et al. Cloning and characterization of a novel intronless lactate dehydrogenase gene in human testis. Int J Mol Med, 2005, 15: 949-953

144 Yin L L, Li J M, Zhou Z M, et al. Identification of a novel testis-specific gene and itspotential roles in testis development/ spermatogenesis. Asian J Androl, 2005, 7: 127-137
145 Zheng Y, Zhou Z M, Min X, et al. Identification and characterization of the BGR-like gene with a potential role in human testicular development/spermatogenesis. Asian J Androl, 2005, 7: 21-32

146 Xiao J, Xu M, Li J, et al. NYD-SP6, a novel gene potentially involved in regulating testicular development/spermatogenesis. Biochem Biophys Res Commun, 2002, 291: 101-110

147 Cheng L J, Li J M, Chen J, et al. NYD-SP16, a novel gene associated with spermatogenesis of human testis. Biol Reprod, 2003, 68: 190-198

148 Li Z, Yao K, Cao Y. Molecular cloning of a novel tissue-specific gene from human nasopharyngeal epithelium. Gene, 1999, 237: 235-240

149 Nie X, Zhang B, Li X, et al. Cloning, expression, and mutation analysis of NOR1, a novel human gene down-regulated in HNE1 nasopharyngeal carcinoma cell line. J Cancer Res Clin Oncol, 2003, 129: 410-414

150 Li Y, Chen Z. Molecular cloning and characterization of LCRG1 a novel gene localized to the tumor suppressor locus D17S800D17S930. Cancer Lett, 2004, 209: 75-85

151 LI Z H, Cao L, Xiang J J, et al. Expression of tumor related gene NAG6 in gastric cancer and restriction fragment length polymorphism analysis. World J Gastroenterol, 2004, 10: 1361-1364

152 Zhang Q, Wang J, Li G, et al. Expression and functional characterization of LRRC4, a novel brain-specific member of the LRR superfamily. FEBS Lett, 2005, 579: 3674-3682

153 Dan L, Li F Y, Guang X L. Molecular cloning and expression analysis of a novel human testis-specific gene. Yi Chuan Xue Bao, 2004, 31: 545-551

154 Liu S F, Li L Y, Fu J J, et al. Rapid identification of human testis spermatocyte apoptosis- related gene, TSARG2, by nested PCR and draft human genome searching. Sheng Wu Hua Xue Yu Sheng Wu Wu Li Xue Bao (Shanghai), 2002, 34: 378-382

155 Liu G, Lu G, Fu J, et al. Molecular cloning of TSARG3 gene related to apoptosis in human spermatogenic cells. Zhonghua Yi Xue Yi Chuan Xue Za Zhi, 2003, 20: 107-110

156 Qi X, Li Y, Xiao J, et al. Activation of transcriptional activities of AP-1 and SRE by a new zinc-finger protein ZNF641. Biochem Biophys Res Commun, 2005, 339: 1155-1164

157 Cheng Y, Wang Y, Li Y, et al.A novel human gene ZNF415 with five isoforms inhibits AP-1- and p53-mediated transcriptional activity. Biochem Biophys Res Commun, 2006, 351: 33-39

158 Zhao Y, Zhou L, Liu B, et al. ZNF325, a novel human zinc finger protein with a RBaK-like RB-binding domain, inhibits AP-1- and SRE-mediated transcriptional activity. Biochem Biophys Res Commun, 2006, 346: 1191-1199

159 Huang X, Yuan W, Huang W, et al. ZNF569, a novel KRAB-containing zinc finger protein, suppresses MAPK signaling pathway. Biochem Biophys Res Commun, 2006, 346: 621-628

160 Xiang Z, Yuan W, Luo N, et al. A novel human zinc finger protein ZNF540 interacts with MVP and inhibits transcriptional activities of the ERK signal pathway. Biochem Biophys Res Commun, 2006, 347: 288-296

161 Liu F, Zhu C, Xiao J, et al. A novel human KRAB-containing zinc-finger gene ZNF446 inhibits transcriptional activities of SRE and AP-1. Biochem Biophys Res Commun, 2005, 333: 5-13

162 Yang H, Yuan W, Wang Y, et al. ZNF649, a novel Kruppel type zinc-finger protein, functions as a transcriptional suppressor. Biochem Biophys Res Commun, 2005, 333: 206-215

163 Ouyang P and Sugrue, S P. Characterization of pinin, a novel protein associated with thedesmosome-intermediate filament complex. J Cell Biol, 1996, 135: 1027-1042

164 Lai M C, Kuo H W, Chang W C, et al. A novel splicing regulator shares a nuclear import pathway with SR proteins. EMBO J, 2003, 22: 1359-1369

165 Hung L Y, Tang C J, Tang T K. Protein 4.1 R-135 interacts with a novel centrosomal protein (CPAP) which is associated with the gamma-tubulin complex. Mol Cell Bio, 2000, 20: 7813-7825

166 Pai C Y, Chen H K, Sheu H L, et al. Cell-cycle-dependent alterations of a highly phosphorylated nucleolar protein p130 are associ- 
ated with nucleologenesis. J Cell Sci, 1995, 108: 1911-1920

167 So C W, Caldas C, Liu M M, et al. EEN encodes for a member of a new family of proteins containing an Src homology 3 domain and is the third gene located on chromosome 19p13 that fuses to MLL in human leukemia. Proc Natl Acad Sci USA, 1997, 94: 25632568

168 Yam J W, Jin D Y, So C W, et al. Identification and characterization of EBP, a novel EEN binding protein that inhibits Ras signaling and is recruited into the nucleus by the MLL-EEN fusion protein. Blood, 2004, 103: 1445-1453

169 Tang W K, Chui C H, Fatima S, et al. Oncogenic properties of a novel gene JK-1 located in chromosome $5 \mathrm{p}$ and its overexpression in human esophageal squamous cell carcinoma. Int J Mol Med, 2007, 19: $915-923$

Open Access This article is distributed under the terms of the Creative Commons Attribution License which permits any use, distribution, and reproduction in any medium, provided the original author(s) and source are credited. 